\title{
Trace Detection of Research Department Explosive (RDX) using Electrochemical Gas Sensor
}

\author{
Praveen Kumar Sekhar* and Francesca Wignes \\ Nanomaterials and Sensors Laboratory, School of Engineering and Computer Science \\ Washington State University Vancouver \\ 14204 NE Salmon Creek Avenue, Vancouver, 98686, USA. \\ praveen.sekhar@wsu.edu
}

\begin{abstract}
Scientific interest in the detection of the high-explosive research department explosive (RDX) continues to escalate from a national security perspective. In this article, selective and sensitive detection of trace RDX is demonstrated. The screening system is based on a concentrator front end and electrochemical potentiometric gas sensor as the backend. Preferential hydrocarbon and nitrogen oxide(s) mixed potential sensors with integrated heaters were used to capture the signature of the explosive. Quantitative measurements based on hydrocarbon and nitrogen oxide sensor responses indicated that the detector sensitivity scaled proportionally with the mass of RDX (down to $20 \mathrm{ng}$ ). The sensitivity was found to depend on the flow rate. The sensitivity was found to increase with increasing flow rate. A $42 \%$ increase in sensitivity was observed with a flow rate of $500 \mathrm{ml} / \mathrm{min}$. This detection technique has the potential to become an orthogonal technique to the existing explosive screening technologies for reducing the number of false positives/false negatives in a cost-effective manner.
\end{abstract}

Keywords: RDX, Mixed Potential, Gas Sensor, Sensitivity, Selectivity, Electrochemical

* Corresponding Author 


\section{Introduction}

The 2011 Department of Homeland Security (DHS) Progress Report [1] on 'Implementing 9/11 Committee Recommendations' places an important precedence on improving national security through robust explosive-screening technologies. The detector combination of Gas Chromatography (GC)-Mass Spectrometry (MS) is currently considered as a gold standard [2] for explosives detection. However, the high cost of GC-MS, their bulky size, and the need for an informed end-user has motivated investigations for new screening technologies, which are more cost-effective [3].

Present day commercial threat detection technologies are less capable than needed and suffer from numerous limitations (e.g., low sensitivity and false positives) when used outside well-controlled conditions [4-8]. In addition to sensor performance considerations, there is the matter of cost. For example, the tabletop systems used for screening carry-on baggage can cost around $\$ 65,000$ [9].The United States has more than 400 commercial passenger airports; if equally distributed, several thousand devices might be required, corresponding to a total capital cost for equipment of up to hundreds of millions of dollars. Installation and maintenance costs would be additional. At present, the scent-analysis ability of dogs is used as the baseline to gauge any instrumentation for detecting explosives. Further, dog's olfaction is sensitive enough to detect trace amounts of many compounds, but several factors have inhibited the regular use of canines for passenger screening. Dogs trained in explosives detection can generally only work for brief periods, have significant upkeep costs, are unable to communicate the identity of the detected explosives residue, and require a human handler when performing their detection role.

Chemical sensors, on the other hand have the potential [10] to mimic the incredibly accurate and versatile "canine-nose" system. In particular, electrochemical sensing [11-15] modality holds a great promise in offering portable, low cost, selective, sensitive, rapid and compact solution to threat detection. As probing the vapor phase (instead of solid or liquid) surrounding the potential threat may lead to improved means for explosives detection, electrochemical gas sensors could be a possible solution to screen a diverse palette of explosives. 
Mixed potential sensors are a class of electrochemical devices that develop a non-Nernstian potential due to the difference in the kinetics of the redox reactions at each electrode/electrolyte interface upon exposure to various analytes $[16,17]$. The mixed potential strongly depends on the catalytic and electrocatalytic properties near the three phase interface (electrode/electrolyte/gas), which in turn depend on the operating temperature of the sensor. Unlike the state-of the art and commercially available trace explosive detection systems (such as Ion Mobility Spectrometer), the mixed potential based gas sensors offer a low-cost alternative for screening a diverse palette of explosives with high specificity. The mixed potential based gas sensors leverage the fact that the inevitable gas-phase decomposition of explosives that are made up of $\mathrm{C}, \mathrm{H}, \mathrm{N}, \mathrm{O}$ involve highly predictable and readily-measurable 'breakdown' components such as $\mathrm{NO}, \mathrm{NO}_{2}, \mathrm{CO}, \mathrm{CO}_{2}, \mathrm{C}_{3} \mathrm{H}_{6}, \mathrm{NH}_{2}, \mathrm{NH}_{3}$, etc [18]. The focus of this article is to demonstrate the trace detection of research department explosive (RDX) using selective hydrocarbon (HC) and $\mathrm{NO}_{\mathrm{x}}$ mixed potential gas sensor.

RDX is 1000 times less volatile than 1, 3, 5-trinitrotoluene (TNT), corresponding to a parts-pertrillion vapor pressure under ambient conditions. Compared to other explosives, trace detection of RDX is challenging. However, trace detection of RDX has been reported exploiting surface stress [19], luminescence [20], fluorescence [21], calorimetric [22], colorimetric [23], photoacoustic [24], and optoelectronics [25] based transduction methods. Though detection limits of 1 ng have been reported [26], there is a lack of interference testing and experiments to test the suitability of the techniques in field conditions. Further, the potential cost of deployment of the investigated techniques seems comparable to the cost of existing explosives detector.

Reports on electrochemical detection [27] of RDX looks promising due to the possibility of system miniaturization and reduced field deployment cost. As mentioned earlier, the mixed potential gas sensor work driven largely for the need a new types of emissions monitoring sensors for the lean-burn automotive and heavy vehicle markets to meet new emissions standards - has produced a number of advances in durability, cost, and selectivity. 
In this work, a planar mixed potential sensor with integrated platinum heater is used in the selective $\mathrm{HC}$ and $\mathrm{NO}_{x}$ detection mode. The front end houses a state-of-the-art preconcentrator system [28] (a hand-portable sample collection and preconcentrator device), which, when combined with an appropriate method of detection, is capable of detecting vanishingly faint odors (parts per trillion) of explosives, drugs, and other chemicals. Apart from RDX, TNT and Pentaerythritol tetranitrate (PETN) are used as the analytes to gauge the discrimination capability. Acetonitrile, methanol, and Vitamin E $\left(\mathrm{C}_{29} \mathrm{H}_{50} \mathrm{O}_{2}\right)$ are used as negative controls.

\section{Experimental}

The experimental set-up for explosives detection is shown in figure 1A and figure 1B. The planar sensor was mounted into custom made Macor ${ }^{\circledR}$ sensor holder with compression contact of four Pt-leads for making electrical connection to each of the two sensor and heater leads. The assembly was placed into a specially prepared quartz tube with a sealed end that placed the sensor electrodes in the test gas stream. An O-ring around the Macor ${ }^{\circledR}$ fixture was used to hold the apparatus in place and seal the gas environment. In this "cold-wall" set-up, the Pt-heater is the only source of heat supplied to the sensor components.

The sensor with integrated Pt heater is referred to as the 'stick' sensor configuration. It is a wellknown sensor design for automotive applications. A single sensor was used to measure both the HC and $\mathrm{NO}_{\mathrm{x}}$ gas species exploiting unique properties of this sensor construct [29] under different operating conditions. The $\mathrm{HC}$ and $\mathrm{NO}_{\mathrm{x}}$ stick sensor was made of screen-printed Sr-doped lanthanum chromite as the working electrode and screen-printed Pt as the pseudo-reference and/or counter electrode. The heater pattern was designed to obtain the required heater resistance utilizing a standard Pt heater ink composition. The details of the sensor fabrication can be found in an earlier article [29]. The electrolyte used in the sensor fabrication was Yttria Stabilized Zirconia (YSZ). The thickness of the Pt electrode, metal oxide electrode and the electrolyte were $2 \mathrm{~mm}$ x $2 \mathrm{~mm} \times 3 \mathrm{~mm}$ respectively. The sensor inside the

housing was tuned for preferential $\mathrm{NO}_{\mathrm{x}}$ response by the appropriate application of a current bias [30] and the appropriate choice of the sensor operating temperature. 
Selective HC (figure 2) response was obtained under open-circuit conditions and appropriate selection of the sensor operating temperature. A current bias of $0.3 \mu \mathrm{A}$ was applied to obtain the selective $\mathrm{NO}_{\mathrm{x}}+\mathrm{NH}_{3}$ response (figure 3). Air was used the base gas (partial pressure of oxygen: $21 \%$ ). The HC temperature was maintained at 475 deg $\mathrm{C}$ to maintain the $\mathrm{HC}$ selectivity over other gases. Further, temperature of $475 \mathrm{C}$ was an optimal temperature considering the sensitivity-response time trade off. Increasing the temperature to above 475 deg $\mathrm{C}$ would lower the sensitivity to HCs while lowering below $475 \operatorname{deg} \mathrm{C}$ would make the sensor sluggish. A similar argument holds for the $\mathrm{NO}_{\mathrm{x}}$ sensor. In the $\mathrm{NO}_{\mathrm{x}}$ mode, the operating temperature and the bias influence the interfacial resistance which, in turn, affects the $\mathrm{NO}_{\mathrm{x}}$ sensitivity.

A constant resistance power supply (Model 1450-H, Custom Sensor Solutions, Inc) board was used to precisely control the operating temperature of the sensor as a change in airflow, ambient temperature, or even analyte gas can cause temperature shifts that affect sensor operation. In the $\mathrm{NO}_{\mathrm{x}}$ operating mode, the sensor was maintained at $500 \operatorname{deg} \mathrm{C}$ while the sensor was maintained at $475 \operatorname{deg} \mathrm{C}$ for the HC operating mode. The sensor leads were connected to the 2400 Keithley source meters to monitor the $\mathrm{HC}$ and $\mathrm{NO}_{\mathrm{x}}$ response while the temperature of the surface in contact with the HE samples was recorded through another 2400 Keithley source meter via a Fluke $80 \mathrm{TK}$ thermocouple module. Trace samples of RDX was obtained using Accustandards ${ }^{\mathrm{TM}}$ (high purity analytical calibration standards typically used to calibrate IMS and gas chromatography/mass spectroscopy (GC/MS) analytical instrumentation. The total volume of the samples procured was $1 \mathrm{~mL}$. RDX $(995 \mu \mathrm{g} / \mathrm{mL}$, balance 1:1 acetonitrile and methanol solvent) formed the de minimus quantities of explosives.

The HE/solvent sample was either transferred directly onto the felt using a micropipette or indirectly using a small hot-wire device. Using this latter approach, the high explosives (HE)/solvent mixture was placed onto a small resistive wire. After evaporation of the liquid solvent, an electric current was pulsed through the wire (msec duration) to rapidly increase the vapor pressure of the sample without decomposing it. A separate sampling unit - containing the felt used for sample concentration - pulled a stream of room air through the felt using a high-speed motor with impeller. The HE vapor and particulates 
of HE were subsequently trapped on the surface of the felt [31]. The benefit of using this latter approach over the former is that electrochemical sensor detects only a signature from the explosive compound and not from the solvent. The concentrator felt had a thermocouple spot-welded to it to permit monitoring of the desorption temperature.

After trapping the HE molecules on the surface of the felt, the collector felt module was rapidly heated with high degree of reproducibility $(<0.5 \mathrm{~s})$ to the desired set-point temperature $(185 \mathrm{deg} \mathrm{C})$ in airflow $(300 \mathrm{ml} / \mathrm{min})$. The rapid heating of the collector felt results in the release of HE molecules from the felt surface (they were adsorbed to) directly to the mixed potential gas sensors operating downstream in a glass fixture.

First, the background signal in the absence of explosives vapor was collected for the sensors by flashing the felt without the trace explosives adsorbed on them. Further, RDX concentrations were varied (20 $\mu \mathrm{g}$ down to $20 \mathrm{ng}$, the volumetric units are converted to corresponding mass units) to observe the sensor response. The area under the peak for the $\mathrm{HC}$ and $\mathrm{NO}_{\mathrm{x}}$ sensor is an indicator of the device sensitivity. The ratio of the area under the peak of $\mathrm{HC}$ and $\mathrm{NO}_{\mathrm{x}}$ is an indicator of selectivity. The flow rate was initially fixed at $300 \mathrm{ml} / \mathrm{min}$. Experiments were carried out to monitor the sensitivity as a function of flow rate.

\section{Results and Discussion}

Figure 4 shows the baseline responses of the HC and NOx sensor upon flashing the empty or clean felt. Upon introducing $1 \mu \mathrm{g}$ of $\mathrm{RDX}$, the $\mathrm{HC}$ and $\mathrm{NO}_{\mathrm{x}}$ sensor responses deviated from their sensor baselines with sharp peaks. The integrated peak area for $1 \mu \mathrm{g}$ of RDX for $\mathrm{HC}$ and $\mathrm{NO}_{\mathrm{x}}$ peak were 0.8326 V.s and 0.2675 V.s respectively. The experiments were repeated three times to ensure repeatability. Figure 5 shows the $\mathrm{HC}$ and $\mathrm{NO}_{\mathrm{x}}$ sensor response as a function of RDX concentration respectively. With an increase in the concentration of $\mathrm{RDX}$, the sensor response seems to increase for both $\mathrm{HC}$ and $\mathrm{NO}_{\mathrm{x}}$ sensor. Reiterating, the area under the sensor peaks accounts for the sensitivity and not the signal magnitude (or height). For 20 ng (volumetric unit converted to mass units) of RDX, the integrated peak area for the $\mathrm{HC}$ and $\mathrm{NO}_{\mathrm{x}}$ was found to be 0.2495 V.s and 0.09125 V.s respectively. 
No specific sensor response trend (linear or logarithmic) was observed for both $\mathrm{HC}$ and $\mathrm{NO}_{\mathrm{x}}$ sensor for varying concentrations of RDX, though a linear or log-linear response is typically expected in a mixed potential sensor. Density Functional Theory (DFT) calculations [32] indicate gaseous by-products of RDX decomposition to be $\mathrm{NO}, \mathrm{NO}_{2}, \mathrm{~N}_{2} \mathrm{O}, \mathrm{CO}_{2}$, and $\mathrm{CH}_{2} \mathrm{O}$. It is speculated that the $\mathrm{HC}$ and $\mathrm{NO}_{\mathrm{x}}$ sensors responds to the suite of these gases.

For an accurate understanding of the relationship between the sensitivity and the concentration of the explosives, it is essential to (a) investigate the gas phase decomposition of the explosives at the operating temperature of the sensors, (b) study homogenous (in the system) and heterogeneous catalysis (on the sensor electrodes and electrolyte) as a function of explosives concentration, and (c) thermodynamics and kinetics of gas phase flow of the explosive vapor over hot surfaces.

Next, the flow rate was increased to $400 \mathrm{ml} / \mathrm{min}$ and $500 \mathrm{ml} / \mathrm{min}$ and finally reduced to 200 $\mathrm{ml} / \mathrm{min}$. The RDX concentration was fixed at $1 \mu \mathrm{g}$. Figure 6 shows the effect of the flow rate on the HC sensor response. A $42 \%$ increase in sensitivity was observed when the flow rate was increased from 300 $\mathrm{ml} / \mathrm{min}$ to $500 \mathrm{ml} / \mathrm{min}$. In an electrochemical mixed potential sensor, the higher the flow rate, the thinner the diffusion layer thickness, and thus the higher the mass transfer rate facilitating higher mixed potential. The maximum or limiting current density is attained only when the diffusion limited condition is reached. To reduce the flow-rate dependence of sensors, activities such as covering the working electrode with a gas-permeable membrane has been investigated [33]. By modifying the sensor orientation (perpendicular to the flow rather than parallel) and shortening the tubing length from the felt assembly to the sensor, the sensor response's flow rate dependency was significantly reduced.

To gauge the discrimination capability of the current detection system, the ratio of the integrated peak area of $\mathrm{HC}$ to $\mathrm{NO}_{\mathrm{x}}$ was calculated for RDX, TNT, PETN, Acetonitrile, Methanol, and Vit.E. Table 1 indicates the ratio values. A widely different value of each of the analyte indicates that the $\mathrm{HC} / \mathrm{NO}_{\mathrm{x}}$ ratio can be used as potential discriminatory mechanism to distinguish different explosives and non-explosives. 
The ability to use multiple electrochemical gas sensors tuned to distinct threat chemistries forms the basis for detecting a diverse palette of explosives that fall into one of these functional groups: aliphatic nitro compounds, nitroaromatic compounds, nitramines, nitrate esters, acid salts, azides, and organic peroxides.

Future work includes building a new detector enclosure sensor packaging to permit the use of a dedicated pair of sticks sensors (one optimized for $\mathrm{NO}_{\mathrm{x}}$ and one optimized for $\mathrm{HC}$ response). $\mathrm{The}^{\mathrm{N}} \mathrm{NO}_{\mathrm{x}}$ and $\mathrm{HC}$ responses to an HE sample will be recorded simultaneously rather than in separate experiments. This platform will incorporate its own independent heater and the amount of sample pre-catalysis will be varied and the impact on sensitivity studied.

We will screen explosives with similar chemical formulation such as TNT and DNT; and evaluate the $\mathrm{HC} / \mathrm{NO}_{\mathrm{x}}$ ratio for different explosives to see if this electrochemical fingerprinting approach is a robust method for discrimination. Lastly, recent electrochemical ammonia sensor development work [34] presents the possibility of incorporating a sensor to measure ammonia groups present in many HE. Such an effort will enable the detection and discrimination of a wider palette of explosives.

\section{Conclusions}

The article reports on the detection of RDX using electrochemical gas sensors. Based on the mixed potential sensing mechanism, a single pre-commercial prototype selective $\mathrm{HC}$ and $\mathrm{NO}_{\mathrm{x}}$ sensor was used to screen various concentrations of RDX. Quantitative measurements based on hydrocarbon and nitrogen oxide sensor responses indicated that the detector sensitivity scaled proportionally with the mass of RDX (down to $20 \mathrm{ng}$ ). The sensitivity was influenced by the flow rate. The sensitivity of the HC sensor was found to be the highest at a flow rate of $500 \mathrm{ml} / \mathrm{min}$ for $1 \mu \mathrm{g}$ of $\mathrm{RDX}$. The ratio of the HC sensor peak to the $\mathrm{NO}_{\mathrm{x}}$ sensor peak seems to impart the selectivity needed in field conditions. In summary, the ability to use multiple electrochemical gas sensors tuned to distinct threat chemistries (e.g., compounds containing one of the breakdown combinations of $\mathrm{C}, \mathrm{H}, \mathrm{N}$ and $\mathrm{O}$ ) might permit the construction of detector systems to screen a diverse palette of threats with lower rates of false positives and negatives. Future work will focus building a dedicated multi-sensor platform and optimizing that platform for improved sensitivity and discrimination ability. 


\section{Acknowledgements}

This material is based upon work supported by the National Science Foundation under Grant No. 1503634.

\section{References}

[1] U.S. Department of Homeland Security: Implementing 9/11 Commission Recommendations. Available:http://www.dhs.gov/xlibrary/assets/implementing-9-11-commission-report-progress2011.pdf

[2] W.M.A. Niessen (Ed.) (2001). Current Practice of Gas Chromatography-Mass Spectrometry, vol.86.

[3] S.Castillo, I.Matilla, J.Miettinen, M.Oresic, and T.Hyotylainen, Data Analysis Tool for Comprehensive Two-Dimensional Gas Chromatography/Time-of-Flight Mass Spectrometry, Anal.Chem., 83 (2011) 3058-3067.

[4] D.S.Moore, Recent Advances in Trace Explosives Detection Instrumentation, Sens. and Imag. 8 (2007) 9-38.

[5] J.Yinon (Ed) (2007). Counterterrorist Detection Techniques of Explosives. $1^{\text {st }}$ Edition, Elsevier, UK.

[6] M.Marshall and J.C. Oxyley (Eds) (2009). Aspects of Explosives Detection, $1^{\text {st }}$ Edition, Elsevier, UK.

[7] J.Barek, J.Fischer, and J.Wang, Voltammetric and Amperometric Detection of Nitrated Explosives (A Review), Sensing in Electroanalysis, 6 (2011) 139-147.

[8] J.S.Caygill, F.Davis, P.J.Seamus, and P.J.Higson, Current Trends in Explosives Detection Techniques, Talanta, 88 (2012) 14-29.

[9] http://homelandsecurityresearch.com/2009/07/us-explosives-trace-detection-etd-technologies$\underline{\text { markets-2010-2014/ }}$

[10] S.Singh, Sensors - An effective approach for the detection of explosives, J.Haz.Materials, 144 (2007) 15-28.

[11] P. Rabenecker, and K. Pinkwart, A Look Behind Electrochemical Detection of Explosives. Propellants Explos. Pyrotech, 34 (2009) 274-279. 
[12] J. Wang (2007). Electrochemical Sensing of Explosives. Electroanalysis, 19 (2007) 415 - 423.

[13] B.J.Privett, J.H.Shin, and, M.H. Schoenfisch, Electrochemical sensors, Anal. Chem., 82 (2010) 4723-4741.

[14] J.R.Windmiller and J.Wang, Wearable Electrochemical Sensors and Biosensors: A Review, Electroanalysis, 25 (2013) 29-46.

[15] F.Ricci, G.Adornetto, and G.Palleschi, A review of experimental aspects of electrochemical immunosensors, Electrchem. Acta., 84 (2012) 74-83.

[16] D.Schonauer, K.Wiesner, M.Fleischer, and R.Moos, Selective mixed potential ammonia exhaust gas sensor, Sens. And Act.B, 140 (2009) 585-590.

[17] N.Miura, G.Lu and N.Yamazoe, Progress in mixed-potential type devices based on solid electrolyte for sensing redox gases, Solid State Ionics, 136-137 (2000) 533-542.

[18] J.C.Oxley, J.L.Smith, and H.Chen, Decomposition of a Multi-Peroxidic Compound: Triacetone Triperoxide (TATP), Propellants, Explosives, Pyrotechnics, 27 (2002) 209- 216.

[19] S.J.Patil, N.Durgakar, and V.Ramagopal Rao, An ultra-sensitive piezoresistive polymer nanocomposite microcantilever sensor electronic nose platform for explosive vapor detection, Sens. and Act.B, 192 (2014) 444-451.

[20] N.Enkin, E.Sharon, E.Golub, and I.Willner, Ag Nanocluster/DNA Hybrids: Functional Modules for the Detection, of Nitroaromatic and RDX Explosives, Nano.Lett. 14 (2014) 4918-4922.

[21] T.L.Andrew and T.M.Swager, A Fluorescence Turn-On Mechanism to Detect High Explosives RDX and PETN, J.Am.Chem.Soc. 129 (2007) 7254-7255.

[22] J.K.Olsen, A.Greve, L.Senesac, T.Thundat and A.Boisen, Differential thermal analysis microsystem for explosive detection, Proc.SPIE, 8031 (2011) 80312-P1-P6.

[23] K.L.Peters, I.Corbin, L.M.Kaufman, K.Zreibe, L.Blanes, and B.R.McCord, Simultaneous colorimetric detection of improvised explosive compounds using microfluidic paper-based analytical devices ( $\mu$ PADs), Anal.Methods, 7 (2015) 63-70.

[24] D.Lee, S.Kim, C W Van Neste, M.Lee, S.Jeon, and T.Thundat, Photoacoustic spectroscopy of 
surface adsorbed molecules using a nanostructured coupled resonator array, Nanotechnology, 25 (2014) 035501-035506.

[25] J.Wojitas, T.Stacewicz, Z.Bielecki, B. Rutecka, R.Medrzycki, and J.Mikolajczyk, Towards optoelectronic detection of explosives, Opto-Electronics Review, 21(2013) 210-219.

[26] D.Lee, S.Kim, S.Jeon, and T.Thundat, Direct Detection and Speciation of Trace Explosives Using a Nanoporous Multifunctional Microcantilever, Anal.Chem., 86 (2014) 5077-5082.

[27] A.M.O’Mahony and J.Wang, Nanomaterial-based electrochemical detection of explosives: a review of recent developments, Anal.Methods., 5 (2013) 4296-4309.

[28] K.L.Linker, F.J.Conrad, C.A.Custer, C.L.Rhykerd, Particle Preconcentrator, US Patent \#5854431, Dec. 29, 1998.

[29] P.K.Sekhar, E.L.Brosha, R.Mukundan, W.Li, M.A.Nelson, P.Palanisamy, and F.H.Garzon, Application of commercial automotive sensor manufacturing methods for NOx/NH3 mixed potential sensors for on-board emissions control, Sens. And Act.B, 144 (2010)112-119.

[30] R.Mukundan, K.Teranishi, E.L.Brosha and F.H.Garzon, Nitrogen oxide sensors based on yttriastabilized zirconia electrolyte and oxide electrodes, Electrochem. Solid State Lett., 10 (2007) J26-J29.

[31] K.L.Linker, F.A.Bouchier, D.W.Hannum, and C.L.Rhykerd, Human portable preconcentrator system, US Patent \#6523393, Aug.12, 2003.

[32] D.Chakraborty, R.P.Muller, S.Dasgupta, and W.A.Goddard III, A detailed model for the decomposition of nitramines: RDX and HMX, Journal of Computer-Aided Materials Design, 8 (2006) 203-212.

[33] D.Lazik and H.Geistlinger, A new method of membrane-based gas measurements, Sens. and Act. A, 117 (2005) 241-251.

[34] J.Tsitron, C.R.Kreller, P.K.Sekhar, R.Mukundan, F.H.Garzon, E.L.Brosha, A.V.Morozov, Bayesian decoding of the ammonia response of a zirconia-based mixed-potential sensor in the presence of hydrocarbon interference, Sens. And Act.B, 192 (2014) 283-293. 


\section{Figure Captions}

Figure 1. Illustration and photographs of the experimental arrangement used for explosives detection by an electrochemical gas sensor. (A) Experiment schematic, and (B) Photograph of the sensing set-up.

Figure 2. Selective Hydrocarbon response at 475 deg C (unbiased).

Figure 3. Selective $\mathrm{NO}_{\mathrm{x}}+\mathrm{NH}_{3}$ response at $500 \mathrm{deg} \mathrm{C}, 0.3 \mu \mathrm{A}$

Figure 4. Baseline (no RDX) response and response to $1 \mu \mathrm{g}$ of $\mathrm{RDX}$ from the $\mathrm{HC}$ and $\mathrm{NO}_{\mathrm{x}}$ sensor.

Figure 5. Integrated peak area of $\mathrm{HC}$ and $\mathrm{NO}_{\mathrm{x}}$ sensor as a function of RDX concentration. The symbol ' $\mathrm{u}$ ' in ug stands for $\mu \mathrm{g}$. The experiment was repeated three times for a fixed flow rate of $300 \mathrm{~mL} / \mathrm{min}$ and the integrated peak area variability is indicated by the error bars.

Figure 6. Integrated peak area of $\mathrm{HC}$ sensor as a function of flow rate. The experiment was repeated three times and the integrated peak area variability is indicated by the error bars.

\section{Table Caption}

Table 1. Potential discrimination mechanism (ratio of $\mathrm{HC} / \mathrm{NO}_{\mathrm{x}}$ ) for explosives. 
Table 1

\begin{tabular}{|l|l|l|l|l|l|l|}
\hline Analyte & RDX & PETN & TNT & Acetonitrile & Methanol & Vit.E \\
\hline $\begin{array}{l}\mathrm{HC} / \mathrm{NO}_{\mathrm{x}} \\
\text { Ratio Range }\end{array}$ & $3.2-4$ & $1.7-2.7$ & $14-30$ & $250-275$ & $10,000-15000$ & 100,000 \\
\hline
\end{tabular}


Type $\mathrm{K}$ thermocouple to record desorber felt $\mathrm{T}$

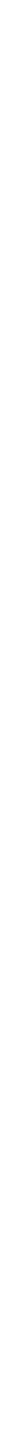

Teflon $^{\mathrm{TM}}$ Swagelock ${ }^{\mathrm{TM}}$ union

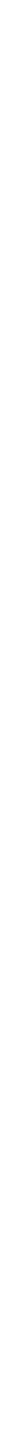

\section{$\mathrm{K}-2400$}

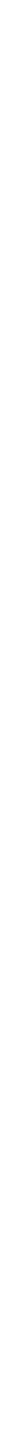

Quartz cap To diaphragm pump

$\overrightarrow{\text { Sample flow }}$

Mixed potential "stick" sensor

O-ring Machined ceramic sensor clamp

Electrochemical sensor package
CRPS Heater Control Board 


\section{Figure $1 b$}

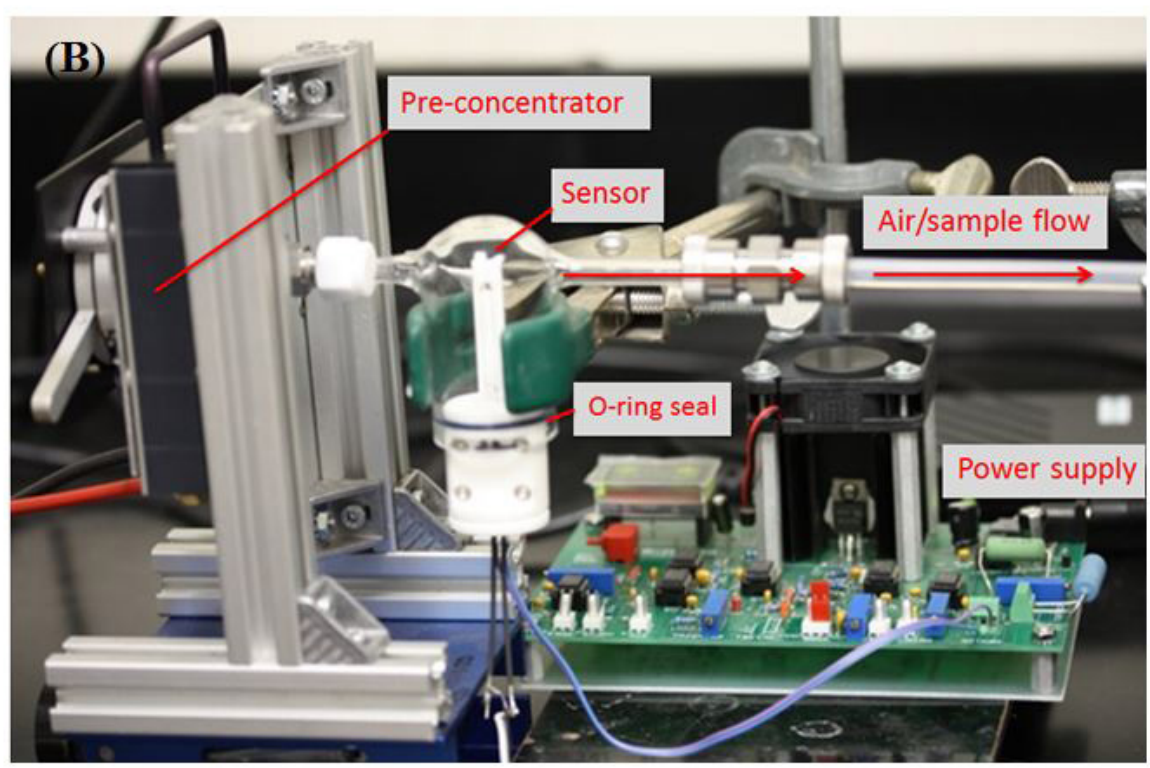




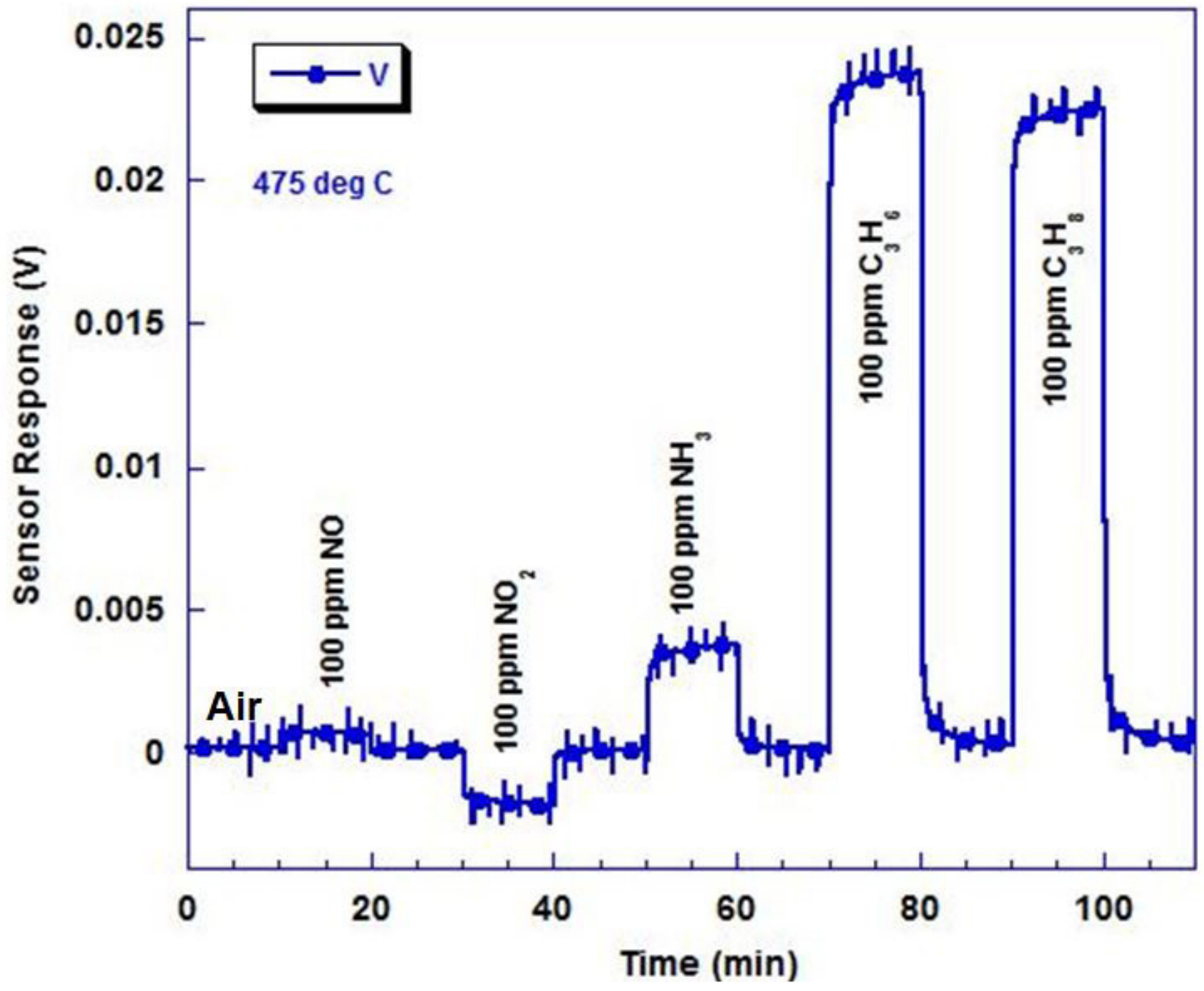




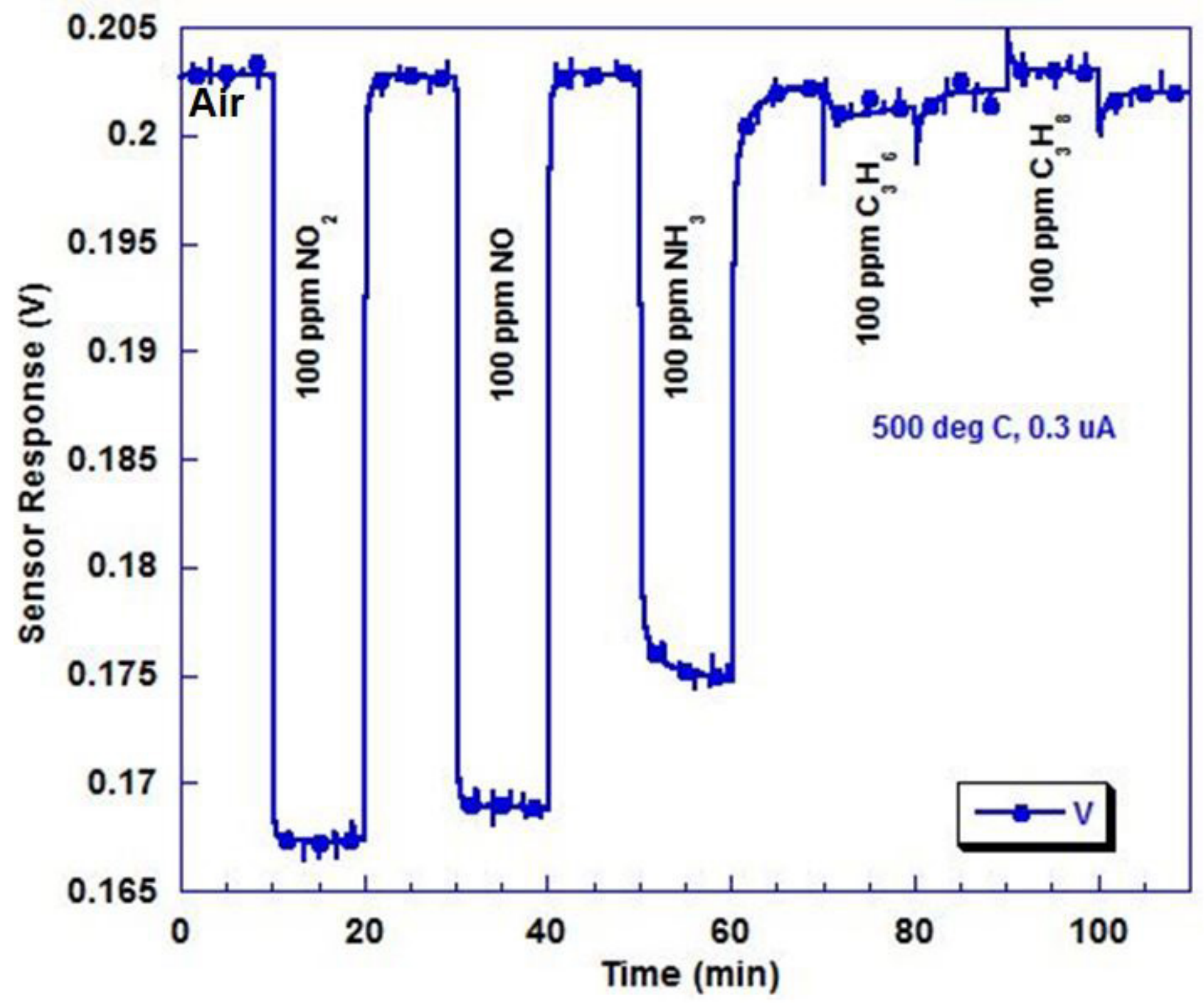


Figure 4

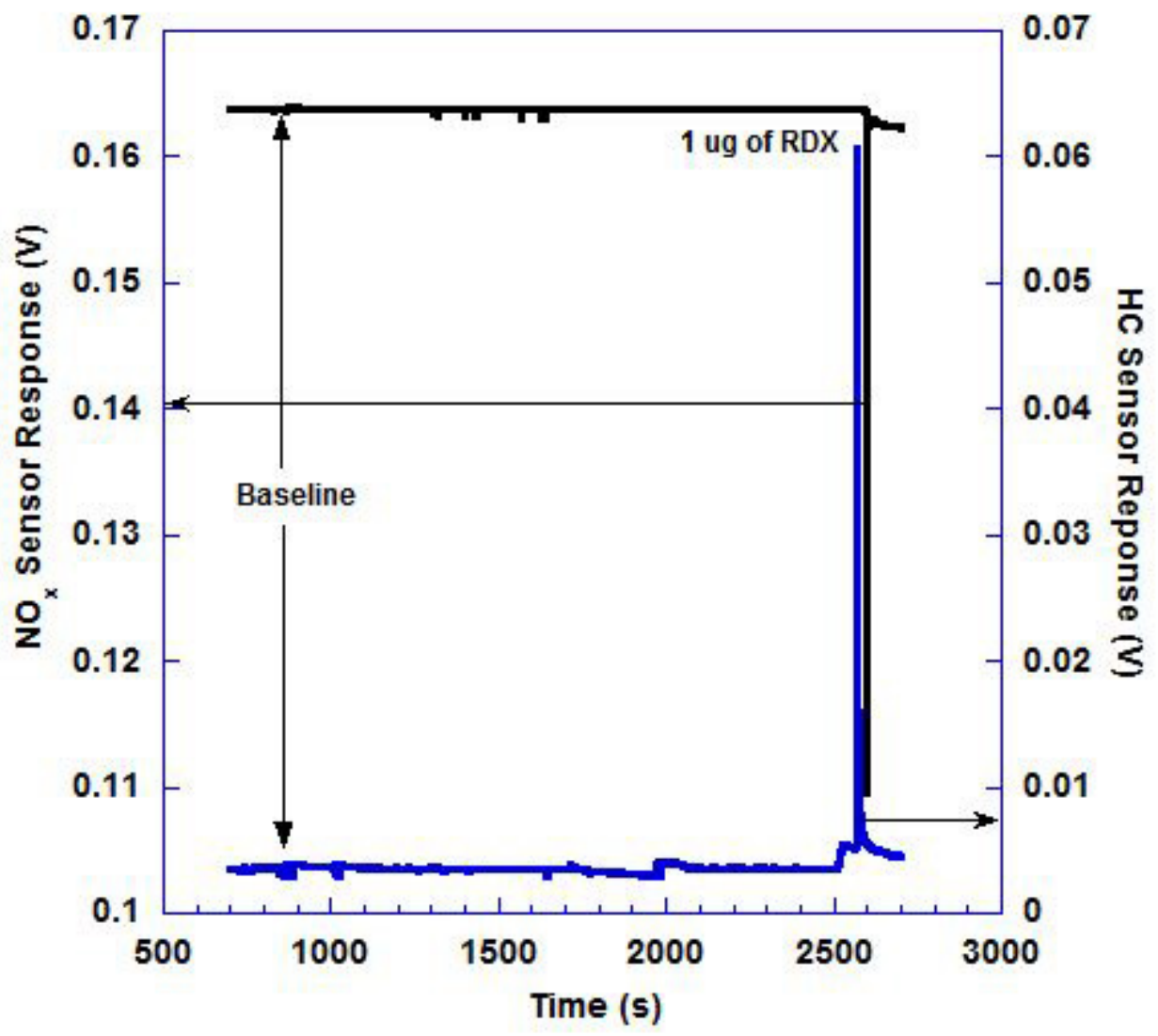




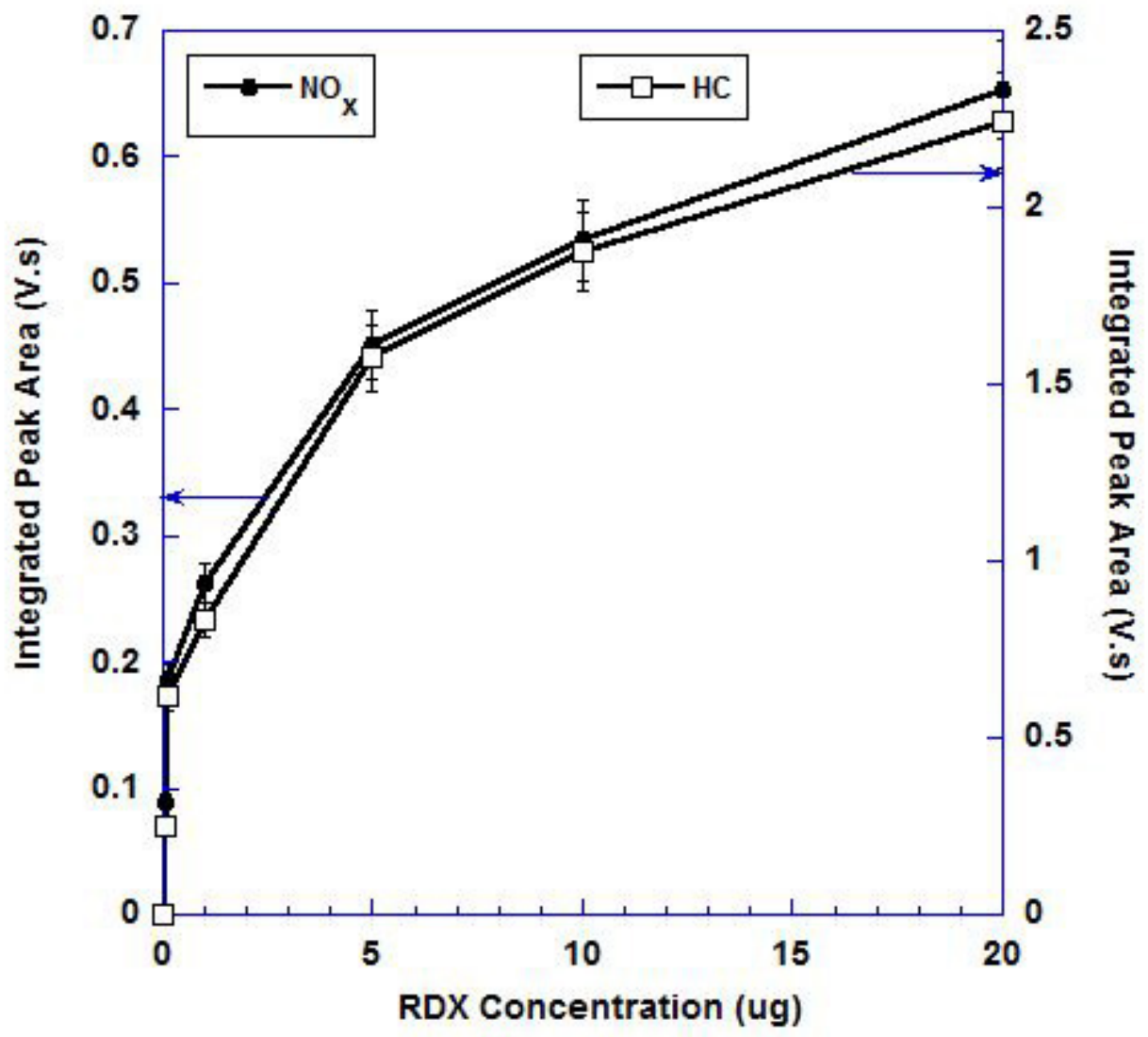




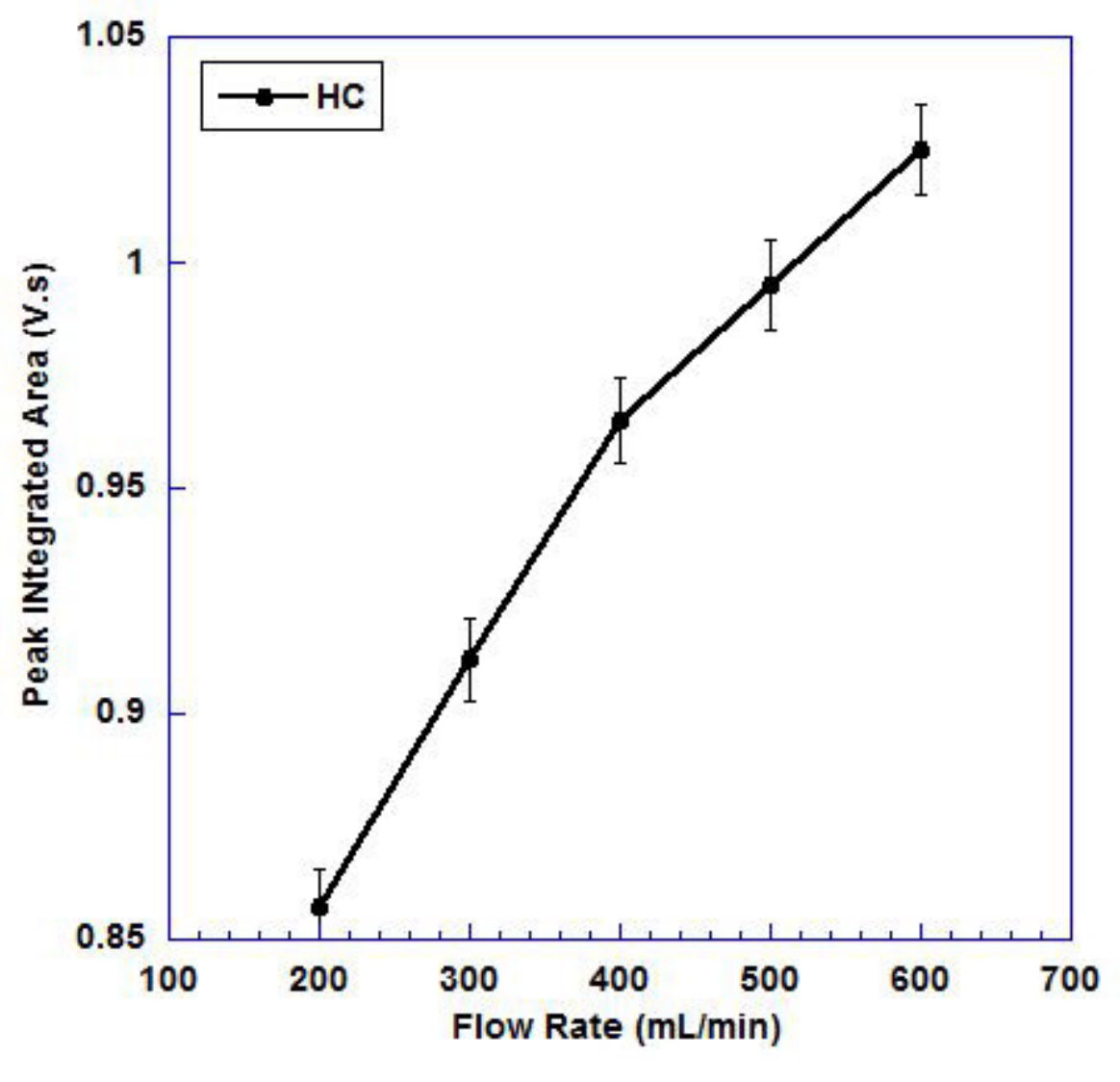

Figure 6

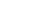




\section{Author Biographies}

Praveen K Sekhar is an assistant professor in the School of Engineering and Computer Science at Washington State University Vancouver, WA since 2011. He leads the Nanomaterials and Sensors Laboratory. Prior to WSU, he was a postdoctoral research associate in the Materials Physics and Applications division (MPA-11) at the Los Alamos National Laboratory for two years. He received his B.E. (distinction) from Coimbatore Institute of Technology, India, in 2001. He received his Masters and Ph.D. in Electrical Engineering from the University of South Florida, Tampa, FL in 2005 and 2008, respectively. His dissertation focused on the synthesis, characterization and applications of silica nanowires won the 'Outstanding Dissertation' award. Currently, his research interests include the development of electrochemical gas sensors and biosensors in addition to materials science and characterization, impedance spectroscopy, microfabrication, and applied statistics.

Francesca Wignes is a senior undergraduate student in electrical engineering at Washington State University, Vancouver. Her research interests are in robotics, sensors, nanostructures and electronics. 